\title{
Detecting Plasma Produced by Laser in a Micromachining System as In-process Control
}

\author{
Cinthya Toro ${ }^{*}$, Carlos Lasorsa ${ }^{*, * *}$ and Carlos Rinaldi ${ }^{* * * *}$ \\ *Comisión Nacional de Energía Atómica (CNEA), Dept. de Micro y Nanotecnología, \\ Av. Gral. Paz 1499, San Martín, Prov. de Buenos Aires, Argentina. \\ E-mail: ctoro@cnea.gov.ar \\ ** Universidad Tecnológica Nacional (UTN), Regional Haedo, Argentina. \\ ${ }^{* * *}$ Consejo Nacional de Investigaciones Cientificas y Técnicas (CONICET), Argentina
}

\begin{abstract}
Automated systems have been used in industries with high-volume production because automation has led, for example, the possibility to reduce costs, increase productivity, and increase accuracy, among others. On the other hand, it is also known that the processing laser is ideal for all kind of controls. In this sense, the amount of material produced and removed by laser irradiation on the surface of the substrate might be used as a control variable. Therefore, plasma detector could be used as part of the control system in the machining process in gaseous environments. This work presents the results of the preliminary characterization of this detector designed to measure the plasma generated during laser machining in air $\left(\mathrm{P}_{\mathrm{amb}}\right.$ and $\left.\mathrm{T}_{\mathrm{amb}}\right)$.
\end{abstract}

DOI: $10.2961 /$ jlmn.2011.03.0009

Keywords: Micromachining, nanosecond laser, films, detecting plasma, in-process control.

\section{Introduction}

During the last decade, laser micro-machining has been developed due to its flexibility and the wide variety of materials that can be processed. Particularly in the MEMS industry, which uses silicon, polymers, metals, and ceramics, is a constantly evolving tool [1-3].

The great volume of fabrication of these devices requires an adequate control during the machining in order to automate the process $[1,4$, and 5]: an open-loop or closed-loop system could improve the precision and more importantly, both the flexibility and quality of the machine tool [4-6]. There are plenty of control systems that could be implemented, because there are very little environmental disturbances in delivering optical energy (principal variable in this process) [4]. This means that it could be possible controlling parameters of the beam, the motorized stage or the workpiece. In the latter, for example, has been tested with measurements of the surface absorption, seam location, temperature and even the product quality [1,4, and 5].

In this work it was developed a plasma detection system. In this regard, it was necessary to obtain the parameters which control the amount of material extracted from the workpiece by measuring of the plasma generated. With this feature it is possible to develop the control system for the carved material deepness [4] during the process, which means an "in-process control".

\section{Experiment}

In this section it is described the design of the detector (Capacitive Detector, CapDet), the micromachining system (in which it was used) and the deposition conditions of film.

\subsection{Design of the detector}

Several conductors ( $\mathrm{Al}, \mathrm{Cu}$ and $\mathrm{Fe}$ ) with different size and, in different geometric conformations (parallel planes, a plane with a ring, two rings) with voltages $\mathrm{V}_{\text {CapDet }}$ from $15 \mathrm{~V}_{\mathrm{DC}}$ to $110 \mathrm{~V}_{\mathrm{DC}}$, have been tested as plasma detectors.

It was observed that signal/noise rate have a greater dependency with the area and with the separation of the conductors. For practical purposes, rectangular areas were selected, since the geometrical configuration produced a low variation (less than $10 \%$ ). On the other hand, $\mathrm{V}_{\text {CapDet }}$ is proportional to $1 / \mathrm{d}_{\text {CapDet }}{ }^{3}$, and it was found that the optimum separation between the rectangular boards was 4 $\mathrm{mm}$ for the maximum $\mathrm{V}_{\mathrm{DC}}$ applied $\left(110 \mathrm{~V}_{\mathrm{DC}}\right)$.

Also, it was studied the location of the sample respect to the electromagnetic field which is between the planes, and it was found no measurable changes. Because of it, the sample was disposed at the end of the CapDet.

In order to use the detector together with the microcontroller it was necessary, that the time constant (RC) should be less than a period of the laser shot $(3 \mathrm{~Hz})$. In this regard, resistors of different values were probed to obtain the time constant of the detector which is a simple $\mathrm{RC}$ circuit $\left(\tau=\mathrm{R}_{\mathrm{eq}} \mathrm{C}_{\mathrm{eq}}=400 \mu \mathrm{s}\right.$, see Figure 1) [7].

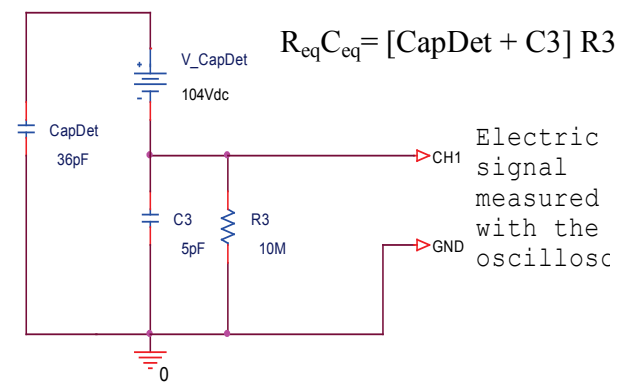

Fig. $1 \mathrm{RC}$ circuit is for simulating the charge and discharge of the capacitor as a result of the electromagnetic disruption caused by the ablation plume.

In this case, the goal was to determine the signal amplitude due to it correlates with the amount of material 
removed [8], for this reason the signal obtained was filtered and the temporal information was missed.

Finally, the CapDet developed consisted of two PCB (printed circuit board) rectangular planes of $4 \mathrm{~cm} \mathrm{x} 3 \mathrm{~cm}$, which were connected to a source of continuous voltage $\left(\mathrm{V}_{\text {CapDet }}\right)$, separated by air. Then, a constant electric field with a spatial distribution given by the conductor's geometry was obtained. This configuration could be considered as a capacitor with its gaseous dielectric, i.e. that the gas trapped between the copper planes is the dielectric. This detector is shown in Figure 2.

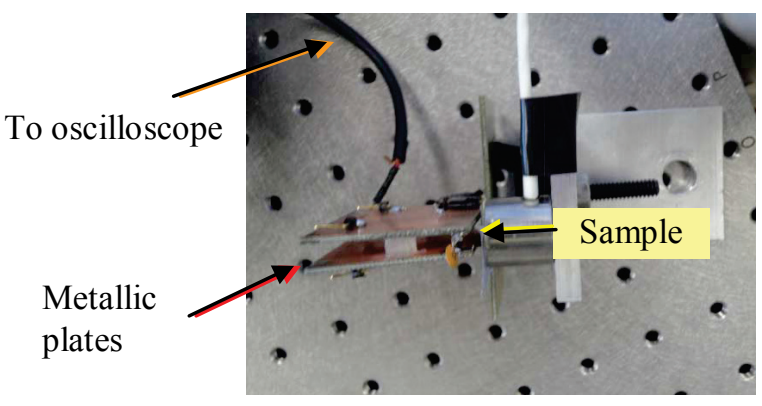

Fig. 2 Plasma detector ad hoc.

A similar setup was reported in references 8 and 9. The results reported in these references had shown that the ablation plume, of pure substrates, causes a disruption that can be measured with high impedance connected in series with the CapDet. Using this configuration it was possible to measure only the positive ions generated [9].

In order to use the detector within this machining system, it was necessary to know the behaviour of the detector for every different type of film, to subsequently finding the control parameters.

The detector characterization was done with a set of spots with a single laser shot. For each spot, the signal from the detector was obtained, analyzed, and the amplitude of the electric signal was plotted as a function of the delivered laser fluence. The same process was repeated for each film. Figure 3 depicts two marks (the two complete circles), each of one was obtained with a single laser shot at a delivered fluence of $170 \mathrm{~mJ} / \mathrm{cm}^{2}$ on a silicon substrate coated with a $\mathrm{Si}_{3} \mathrm{~N}_{4}$ film of $550 \mathrm{~nm}$ thickness.

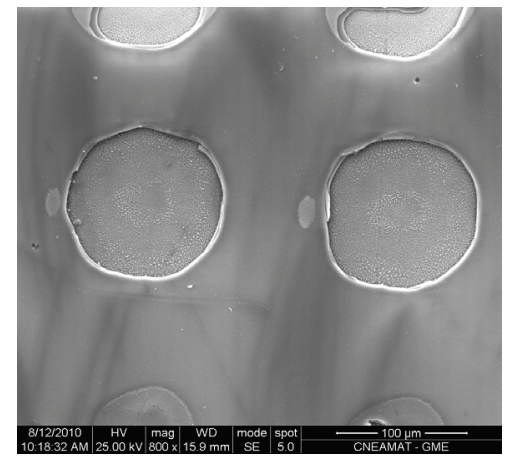

Fig. 3 Micrograph of a sample of c-Si coated with $\mathrm{Si}_{3} \mathrm{~N}_{4}$ of $550 \mathrm{~nm}$ of thickness after interacting with the laser.

For each delivered fluence, $\mathrm{N}$ spots $(\mathrm{N} \geq 10)$ were repeated for statistical purposes, always in fresh zones. And different delivered fluences were used: from $100 \mathrm{~mJ} / \mathrm{cm}^{2}$ to $225 \mathrm{~mJ} / \mathrm{cm}^{2}$, with intervals of 5 and $10 \mathrm{~mJ} / \mathrm{cm}^{2}$.

The electrical signals acquisition were performed using an oscilloscope (Lecroy WaveRunner 44Xi) synchronized with the laser shot, and the complete signal was stored in .csv files for a later analysis.

\subsection{Machining system by laser ablation}

In this work it was used a setup which is shown in the scheme of Figure 4. The machining system consists of Qswitch Nd:YAG laser of Spectra Physics $\left(225 \mathrm{~mJ} / \mathrm{cm}^{2}\right.$ maximum delivered fluence, $8 \mathrm{~ns}$ pulse width, $532 \mathrm{~nm}$ wavelength emission, $3 \mathrm{~Hz}$ pulse repetition frequency) synchronized with a motorized stage system of Thorlabs (NanoMAX300), controlled by an ad hoc software; and a circular pinhole ( $2 \mathrm{~mm}$ diameter $)$ and a lens $(\mathrm{f}=75 \mathrm{~mm})$ in order to concentrate the beam.

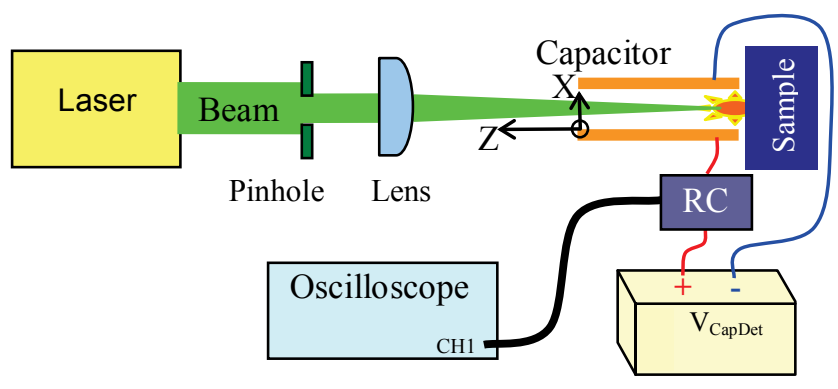

Fig. 4 The schematic of the experimental setup shows the detector connections.

\subsection{Film Deposition}

To obtain the thin films of $\mathrm{SiO}_{2}$ and $\mathrm{Si}_{3} \mathrm{~N}_{4}$ it was used a PE-CVD (Plasma-enhanced chemical vapour deposition) method at temperatures $700{ }^{\circ} \mathrm{C}$, using a mixture of Hexamethyldisilazane (HMDS) $\left(\mathrm{CH}_{3}\right)_{3} \mathrm{SiNHSi}\left(\mathrm{CH}_{3}\right)_{3}$ and nitrogen or oxygen in individual processes [10-12].

They were grown over the single-crystal silicon wafers (c-Si) and the following thicknesses were tested:

$\mathrm{SiO}_{2}: 100 \mathrm{~nm}, 430 \mathrm{~nm}$ and $2400 \mathrm{~nm}$,

$\mathrm{Si}_{3} \mathrm{~N}_{4}: 180 \mathrm{~nm}, 550 \mathrm{~nm}$

The samples were named as follow:

$\mathrm{c}-\mathrm{Si}+\mathrm{SiO}(\alpha \mathrm{nm})$ : c-Si coated with silicon dioxide with a thickness of $\alpha \mathrm{nm}$.

$\mathrm{c}-\mathrm{Si}+\mathrm{SiN}(\beta \mathrm{nm})$ : $\mathrm{c}-\mathrm{Si}$ coated with silicon nitride with a thickness of $\beta \mathrm{nm}$.

Also, these films of $\mathrm{SiO}_{2}$ and $\mathrm{Si}_{3} \mathrm{~N}_{4}$ were used for improving the substrate engraving quality (the substrate is c-Si).

\section{Results and Discussion}

In order to study the effect of the plume position respect to the capacitive plates, a set of measurements were performed changing the $\mathrm{X}$ position of the plate (see Cartesian axis in Figure 4). The results are shown in Figures 5 and 6, where the maximum amplitude indicates the optimum position of the ablation plume where the signal is maximal within the capacitor. And the lower amplitude corresponds with the nearest position to the negative plate. 


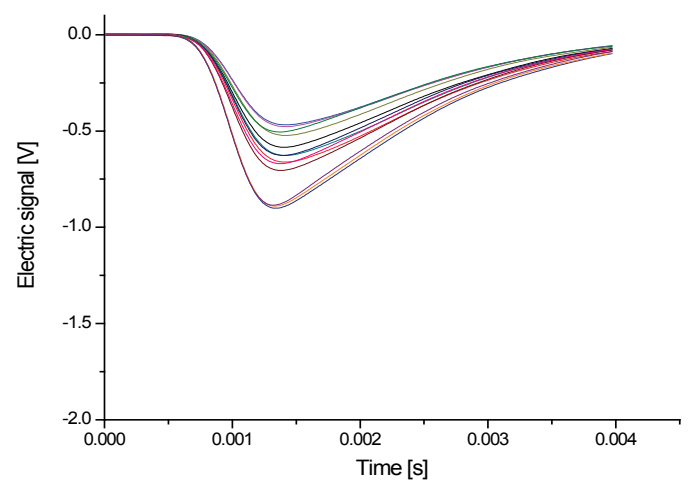

Fig. 5 CapDet signals from irradiating c-Si with 120 $\mathrm{mJ} / \mathrm{cm}^{2}$ of delivered fluence. See the text.

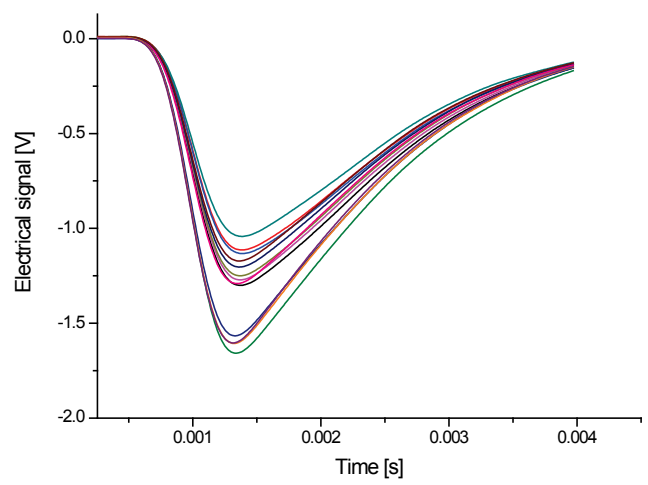

Fig. 6 CapDet signals from irradiating c-Si with 150 $\mathrm{mJ} / \mathrm{cm}^{2}$ of delivered fluence. See the text.

As stated by Villagrán-Muniz et al., the amplitude of the electric signal is proportional to the ablated material. Hence, the experimental results with c-Si which are shown in Figure 7 can be fit according to the equation (1):

$$
M_{J}(\phi)=\left[\frac{A_{1}(\phi)-A_{2}(\phi)}{1+\left(\frac{\phi}{\phi_{C}}\right)^{S_{C}}}\right]+A_{2}(\phi)
$$

Where:

$\mathrm{M}_{\mathrm{J}}(\phi)$ is the amount of removed material (which is proportional to the electric signal, and has units of (mass) $/($ area $)$ (time))

$\phi$ is the delivered fluence of the laser in $\mathrm{J} / \mathrm{cm}^{2}$

$A_{1}$ and $A_{2}$ are $M_{J}$ values in the low and high delivered fluence (the low plateau is the absorption region and the high plateau is the ablation region), and has units of (mass)/(area)(time))

$\mathrm{S}_{\mathrm{C}}$ is an adjustable parameter related to the roughness of the surface (dimensionless), and

$\phi_{\mathrm{C}}$ is a critical delivered fluence whose values indicate the onset of the true ablation process, which then begins to be dominant, in $\mathrm{J} / \mathrm{cm}^{2}$.
The amplitudes were measured and plotted as a function of the delivered fluence used for c-Si and c-Si coated with a thin $\mathrm{SiO}_{2}$ film of $2400 \mathrm{~nm}$ thickness. Figures 7 and 8 show the results for both, respectively. The continuous lines in the figures indicate the adjustments according to the equation (1). Table 1 shows the parameters corresponding to them.

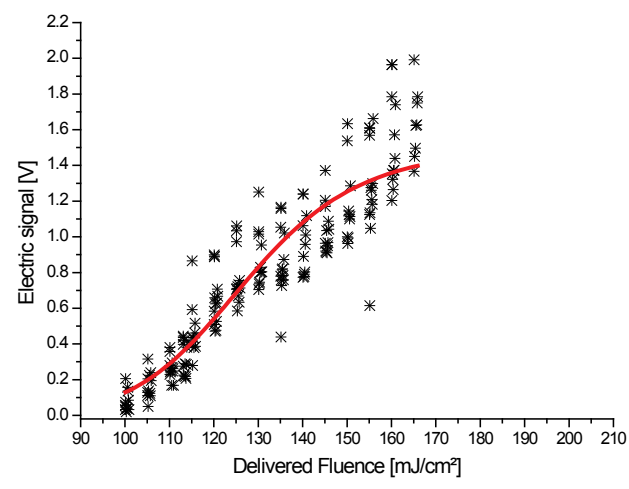

Fig. 7 Maximum values of the signals from CapDet as a function of delivered laser fluence on the c-Si sample, and the line represents the fit with equation (1).

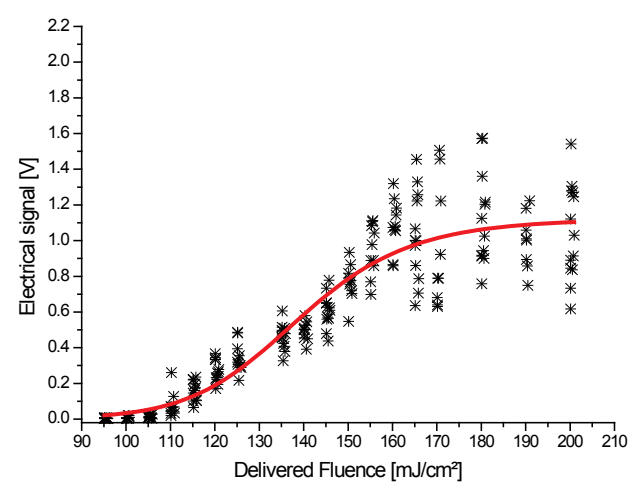

Fig. 8 Maximum values of the signals from CapDet as a function of delivered laser fluence on the c-Si+SiO $(2400$ $\mathrm{nm}$ ) sample, and their fitting with equation (1).

Table 1 Equation (1) parameters obtained from Figures 7 and 8 .

\begin{tabular}{ccc}
\hline Parameter & $\mathrm{c}-\mathrm{Si}$ & $\mathrm{c}-\mathrm{Si}+\mathrm{SiO}(2400 \mathrm{~nm})$ \\
\hline $\mathrm{A}_{1}$ & 0 & 0 \\
$\mathrm{~A}_{2}$ & 1.50 & 1.12 \\
$\phi_{\mathrm{C}}$ & 127.2 & 139.0 \\
$\mathrm{~S}_{\mathrm{C}}$ & 9.9 & 11.0 \\
\hline
\end{tabular}

Looking at Figures 7 and 8, and parameters obtained in Table 1 it is possible to conclude:

1. The $\phi_{\mathrm{C}}$ parameter (critical delivered fluence) for thin $\mathrm{SiO}_{2}$ film is greater than for c-Si, which shows that this material $\left(\mathrm{SiO}_{2}\right.$ film) needs more energy to reach at true ablation process (see reference 8 and 9). 
2. The $\mathrm{S}_{\mathrm{C}}$ parameter for thin $\mathrm{SiO}_{2}$ film is slightly larger than for c-Si, therefore c-Si coated with thin $\mathrm{SiO}_{2}$ film has less surface defects than pure $\mathrm{Si}$, in according with the references 8 and 9 .

For the case of thin films (thickness $<1000 \mathrm{~nm}$ ), the procedure applied was the same and the results showed that the substrate behaviour is different, as can be seen from Figures 9, 10, 11 and 12; where more than 2 plateaus were observed. Even so, the measurements could be adjusted with two equations like as equation (1), whose parameters (for $\mathrm{SiO}_{2}$ films) are shown in Tables 2 and 3.

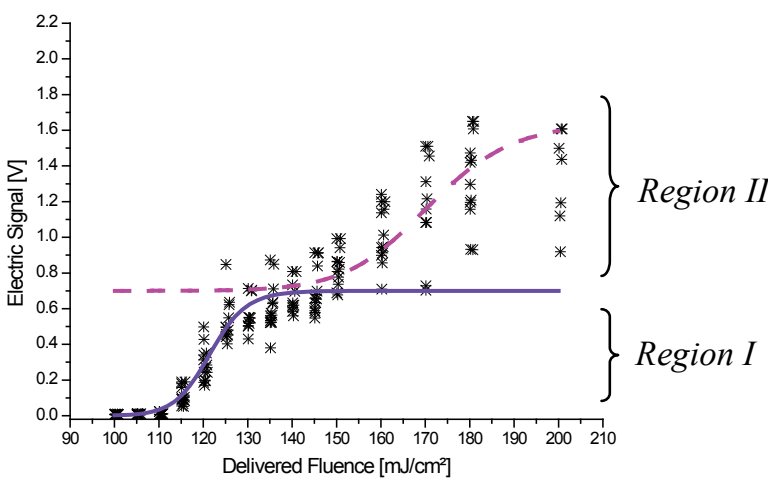

Fig. 9 Maxima of the signals from the detector as a function of the delivered fluence for $\mathrm{c}-\mathrm{Si}+\mathrm{SiO}(110 \mathrm{~nm})$, and their fitting with 2 equations like equation (1). See the text.

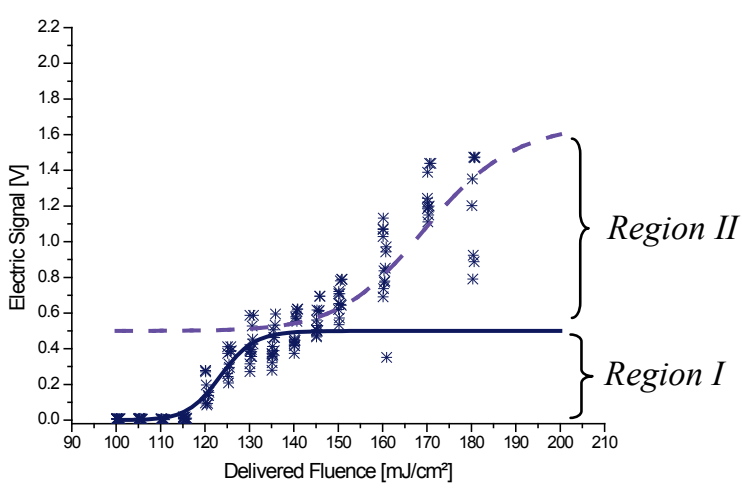

Fig. 10 Maxima of the signals from the detector as a function of the delivered fluence for $\mathrm{c}-\mathrm{Si}+\mathrm{SiO}(220 \mathrm{~nm})$, and their fitting with 2 equations like equation (1). See the text.

It can be seen from Figures 9 and 10 and from the data in Tables 2 and 3 that two zones appear:

The first one (Region I) corresponds to the film ablation and for both, the roughness parameter $\mathrm{S}_{\mathrm{C}}$ is similar, and $\phi_{\mathrm{C}}$, too. In the second (Region II), a similar behaviour is observed, and it corresponds to the silicon substrate ablation. Comparing both zones, the $\mathrm{S}_{\mathrm{C}}$ parameter indicates (31 for region one, and 18 for region two) that the c-Si coated has less defects than pure silicon.
Table 2 The equations parameters obtained from Region I of Figures 9 and 10.

\begin{tabular}{ccc}
\hline Parameter & $\mathrm{c}-\mathrm{Si}+\mathrm{SiO}(110 \mathrm{~nm})$ & $\mathrm{c}-\mathrm{Si}+\mathrm{SiO}(220 \mathrm{~nm})$ \\
\hline $\mathrm{A}_{1}$ & 0 & 0 \\
$\mathrm{~A}_{2}$ & 0.7 & 0.5 \\
$\phi_{\mathrm{C}}$ & 121 & 123 \\
$\mathrm{~S}_{\mathrm{C}}$ & 31 & 33 \\
\hline
\end{tabular}

Table 3 The equations parameters obtained from Region II of Figures 9 and 10.

\begin{tabular}{ccc}
\hline Parameter & $\mathrm{c}-\mathrm{Si}+\mathrm{SiO}(110 \mathrm{~nm})$ & $\mathrm{c}-\mathrm{Si}+\mathrm{SiO}(220 \mathrm{~nm})$ \\
\hline $\mathrm{A}_{1}$ & 0.7 & 0.5 \\
$\mathrm{~A}_{2}$ & 1.6 & 1.7 \\
$\phi_{\mathrm{C}}$ & 170 & 170 \\
$\mathrm{~S}_{\mathrm{C}}$ & 18 & 18 \\
\hline
\end{tabular}

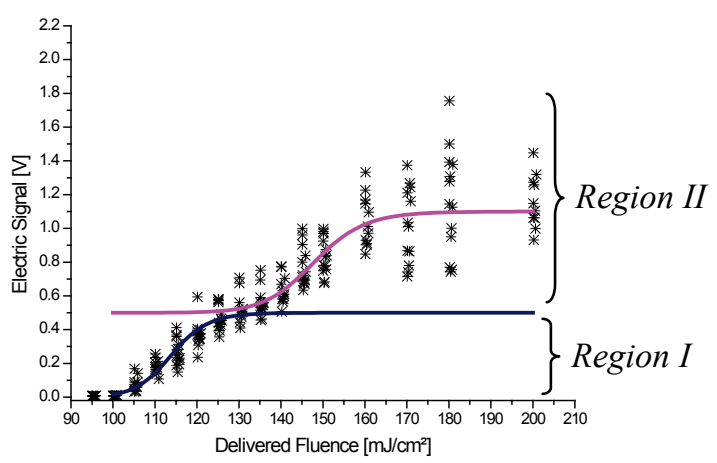

Fig. 11 Maxima of the signals from the detector as a function of the delivered fluence for $\mathrm{c}-\mathrm{Si}+\mathrm{SiN}(70 \mathrm{~nm})$, and their fitting with 2 equations like equation (1).

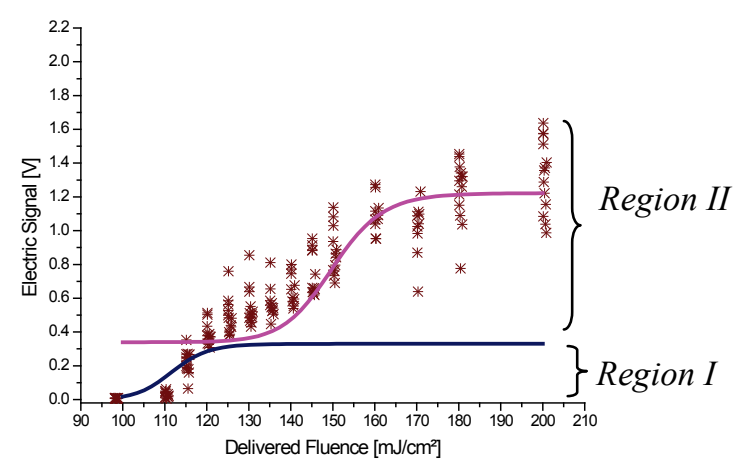

Fig. 12 Maxima of the signals from the detector as a function of the delivered fluence for c-Si+SiN $(550 \mathrm{~nm})$, and their fitting with 2 equations like equation (1). 
Finally, the same behaviour it was observed in the case of c-Si coated with $\mathrm{Si}_{3} \mathrm{~N}_{4}$ films. As it can be seen from Figures 11 and 12, a middle plateau it was reached when the film is completely removed, and the third one it was achieved when the surface substrate (c-Si) has been ablated.

\section{Conclusions}

The control of the material extracted pulse by pulse during the machining, gives a quality domain with the best resolution of the pulsed laser machining. In this work it was shown a plasma detector to measure the material ablated by one laser shot.

Also, the prototype developed enables to study thin films effects on the ablation process.

In this sense, the correlation between the parameters of the equation (1) and different films give the control on the ablated material.

\section{Acknowledgments}

Financial support of this work was provided by the Agencia Nacional de Promoción Científica y Tecnológica.

\section{References}

[1] Cornelius T. Leondes: "MEMS/NEMS Handbook Techniques and Applications. Manufacturing Methods”, ed. by Springer (LA-USA, 2006) Vol. 3, Ch. 4. p. 187-291.
[2] M. R. Rejab, T. T. Mon, M. F. Rashid, N. S. Shalahim and M. F. Ismail: International Journal of Recent Trends in Engineering, Vol. 1 No. 5(2009), p. 105-109.

[3] M. Amer, M. El-Ashry, L. Dosser, K. Hix, J. Maguire, and B. Irwin: Applied Surface Science 242 (2005), p. 162-167.

[4] William M. Steen: "Laser Material Processing", ed. By Springer-Verlag (London, 1991), Chapter 7 p. 220.

[5] Narendra B. Dahotre, Sandip P. Harimkar: "Laser Fabrication and Machining of Materials", ed. by Springer (USA, 2008), Ch. 6 p. 207-246.

[6] E. V. Bordatchev, S. K. Nikumb: Integrating Manufacturing Technologies Institute, National Research of Canada.

[7] M. E. Van Valkenburg: “Análisis de Redes", ed. Limusa Wiley (1983).

[8] M. Villagran-Muñiz, H. Sobral, C. A. Rinaldi, I. Cabanillas-Vidosa, and J. C. Ferrero: Journal of Applied Physics, 104, (2008) p. 103112.

[9] H. Sobral and M. Villagrán-Muniz, F. Bredice: Journal of Applied Physics, 98, (2005) p. 083305.

[10] C.A. Lasorsa, P.M. Perillo, P.J. Morando: Surface and Coatings Technology 204, (2010).

[11] C. Lasorsa, P. J. Morando, A. Rodrigo: Surface and Coatings Technology 194, (2005).

[12] S.Yan, H Maeda, J.-I- Hayashi, K Kusakabe, S Morooka y Y. Okubo, J. Mat. Sc. 28, 1829, (1993).

(Received: July 22, 2011, Accepted: November 18, 2011) 